\title{
South African Perspective of Extrinsic Wine Label Cues
}

\author{
By Salomien Boshoff* \\ Petro-Mari Malherbe
}

In this paper, we describe the key elements to wine packaging. Through a two-phase methodology we determine the extrinsic wine label cues that influence the quality perception and purchase intention of the consumer. The first phase was a selfadministrative questionnaire (80 respondents) and the second phase an eye-tracking method (44 participants). Phase one's results showed the importance of the front label and brand name. Phase two of the methodology again highlighted the importance of a known brand name, a classical look and feel, the importance of the visibility of the grape variety, terms like "reserve" or "limited edition". The images on the bottle can have a negative influence on the quality perception and purchase intention if not wine related.

Keywords: Extrinsic packaging cues, Quality and price perception, Wine purchase.

\section{Introduction}

Packaging is a strong line of communication between a product and consumer in store (Barber and Almanza 2006: 96, Thomas and Pickering 2003: 58) and contributes to the visual extrinsic cues that consumers use to predict the quality and the price of the wine, which influence their purchase intention (Roma et al. 2013: 2776). Packaging indicates a number of characteristics of the wine to the consumers, thus guiding the consumer towards forming a certain perception of the wine, before tasting it (Barber and Almanza 2006: 97, Barber et al. 2006: 228, Prendergast and Pitt 1996: 69, Roma et al. 2013: 2776, Sáenz-Navajas et al. 2013: 45). Consumers use both an intrinsic or/and extrinsic cues to simplify the purchasing decision (Corduas et al. 2013). Corduas et al. (2013) concluded that consumers make more use of extrinsic cues. Orth and Malkewitz (2006) showed that external cues on packaging are especially important to consumers if the brand is unknown to them and consumers make use of the visual extrinsic cues, all present on the packaging and label of the wine bottle, to predict the characteristics and qualities of a specific bottle of wine (Sherman and Tuten 2011). Consumers form a perception about a specific bottle of wine by just looking at it and can possibly make a purchase decision based on this perception (Prendergast and Pitt 1996: 69, Sáenz-Navajas et al. 2013: 2776). By examining the different design elements of wine packaging, South African Pinotage wine marketers can

\footnotetext{
* Junior Lecturer, University of the Free State, South Africa.

${ }^{\dagger}$ University of the Free State, South Africa.
} 
determine how they can influence consumers' perceptions (price and quality) and purchase intention.

\section{Literature Review}

Effective packaging can increase visibility amongst competitors, reinforce brand image and enhance competitive advantage (Bhattacharjee and Bhattacharjee 2005: 202). Packaging is an important factor that persuades consumers' during their product choices (Silayoi and Speece 2004: 623) and the elements of the wine packaging like the label, logo design, method of closure and type of container all contributes to the quality prediction by the consumer (Barber and Almanza 2006: 95, Sherman and Tuten 2011: 230). The total packaging, enhanced by the design and information presented, directly reflects the quality of the product and influence consumers' purchase intention (Atkin and Johnson 2010, Chaney 2000, Henley et al. 2011, Sherman and Tuten 2011).

\section{Wine Packaging Elements}

Four key design elements of wine packaging namely brand logo, brand name, front label information and lastly the back label was identified by Thomas and Pickering (2003). However other elements have been identified by later researchers like the label design, shape, size, colour and type of closure of the bottle (Barber and Almanza 2006), the typography, colour scheme on the label and visual imagery (Boudreaux and Palmer 2007, Orth and Malkewitz 2006), grape variety (Thomas 2000, Orth and Malkewitz 2006) and awards information and adornments (Orth and Malkewitz 2006). Based on a theoretical analysis of previous literature two types of design elements were identified. Firstly the visual and design elements (shape, size, colour of the bottle; typography; visual imagery and label design; methods of closure and finishes and colour schemes used) and secondly the informational elements (front and back label; awards and brand name). According to Silayoi and Speece (2004) the informational elements of the packaging addresses the cognitive decision making process and in contrast the visual elements of packaging relate more to the affective decision making. Thus, the visual elements spark up emotions regarding the specific wine while the informational elements help consumers to make a rational decision by considering the features of the product (Hoyer and MacInnes 2010). In the next two sections the two types of design elements (visual and design elements and informational elements) will be discussed with reference to each component of these elements. The three bottles of wine that were chosen to use in this study represented the different comments of these packaging elements. 


\section{Design and Visual Elements}

The shape of the bottle influences the consumer's perception of the volume of the product (Deng 2009: 148). There are five common bottle shapes (Figure 1): The "Bordeaux" style made for red and white wines (A), the "Burgundy" also commonly used for both red and white wines (B), the "Champange" bottle (C), fourth type known as the "Hoch" (D) and the last style is used for fortified wines such as Port, Sherry and Muscadel (E) (Douglasgreen 2011). Shape A and B (Figure 1) are mostly used for red wines, thus Pinotage.

Figure 1. Different Wine Bottle Shapes

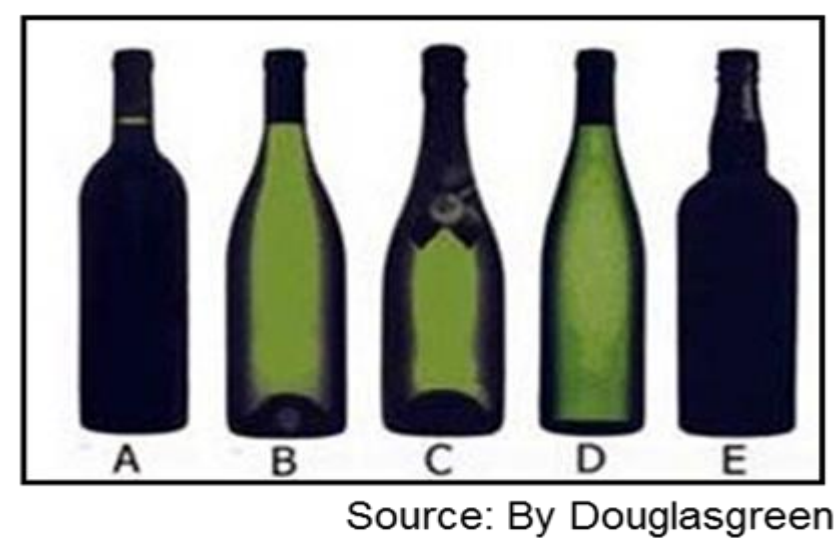

Source: Douglasgreen (2011).

The shape of a bottle has a functional as well as symbolic value. Firstly the shape and size relates to the use, carrying and the storage of the product. The colour of the bottle helps the consumer to classify the wine variety and in some cases show off the colour of the wine, all important elements that leads to a specific perception of the wine (Silayoi and Speece 2004: 626). Wineries believe that expensive wines need to express a sense of importance to the buyers through uniquely shaped bottles (Orth and Malkewitz 2006).

The typography on the bottle also leads to classification by the consumer. Bold, large, roman and uppercase letters are used for elegant products, while serif and sans serif typographies are used for more accessible products with a reasonable price (Louw and Kimber 2007). Modern clean typeface and style are more likely to be used with the new modern layouts (Boudreaux and Palmer 2007: 184).

There are generally three types of label designs: conservative or traditional, contemporary and the novelty label (Sherman and Tuten 2011: 231). A conservative and traditional label typically includes the coat-of-arms, a picture or drawing of the vineries or chateaux. Classic labels are more liked by a consumer group that have a higher subjective wine knowledge, and the results showed that these labels lead to a higher purchase intention of red wine (Chrea et al. 2011: 20). Secondly with the contemporary label includes animals 
or other creative visual images, with less information on the label. SáenzNavajas et al. (2013: 51) suggests that this type of label indicates a low quality wine. On the last genre, novelty- there is no standard pairings with wine, like giraffes or hippopotamus with sometimes fun and humorous associations. In a study by Boudreaux and Palmer (2007: 183) they found that the image presented on the label had a greater effect on the purchase intention than the colour and the layout of the label. Consumers prefer the traditional and conservative images more than the modern or novel labels. Preferences are stronger towards grape motifs or vineyards than unusual animals. Furthermore consumers perceive labels with coat-of-arms images as good quality and upperclass.

The type of closure, cork or screw top influences the consumers' perception of the wine. Consumers consider a cork top as good quality wine and a screw top as poor quality wine and that the type of closure are more important to consumers than the bottle shape or colour used (Barber and Almanza 2006: 95). In a later study Barber et al. (2006: 230) called for research on the wine closure style on consumer purchase decision.

Colour contributes to the notice ability as well as the image of a product (Van Biljon and Jansen van Rensburg 2011: 9555, Immonem 2010). Wine packaging that is of good quality use more traditional dark and rich colours, while less expensive wines use more non-traditional brighter colours on their labels (Boudreaux and Palmer 2007: 183). According to Boudreaux and Palmer (2007: 183) when bright coloured wine packaging are used consumers perceive it as exciting and imaginative, while successful, desirable and expensive wine brands use navy, burgundy or colours from the neutral colour palettes.

\section{Informational Elements}

Labels are the first source of information to the consumer during the wine buying decision making process (Barber and Almanza 2006: 95) and includes the wine style, region, producer, grape varietal, vintage, brand name and communicates the feel of the brand itself (Charters 2003: 15). The front label, perceived as more important than the back label (Thomas and Pickering 2003: 72), generally evokes consumers' attention and interest in contrast to the back label that mainly gives information regarding the wine (Henley et al. 2011: 17).

The results of Barber et al. (2006: 229) study showed that regardless of the label design, consumers use the front label as an information source for the following: style of the wine, cultivar, vintage, location of winery and description of winery. Consumers would often make a purchase decision based on the front label only, without glazing at the back label (Barber and Almanza 2006: 96). Front labels set the standards by which the wine will be judged (Barber and Almanza 2006: 95, Chaney 2000: 15, Olsen et al. 2003: 48, Thomas and Pickering 2003: 73). The back label provides information about the producers, quality of the wine, style of the wine, a short description of the wine, alcohol percentage, grape variety and volume in the bottle (Barber and Almanza 2006: 96, Charter et al. 1999: 180, Henley et al. 2011: 17). The style 
of the wine and the description of the wine are perceived as the most important cues on the back label (Barber and Almanza 2006). McGarry Wolf and Thompson (2010: 8) declared that a consistent number of consumers that the information on the back label into account when buying a bottle of wine. In contrast Sáenz-Navajas et al. (2013: 52) declared that the information on the back label have no effect on the quality perception.

The wine's brand name is a quality indicator of the wine (Sherman and Tuten 2011: 231) and according to Mueller and Lockshin (2008) influence the consumers' wine decision making process. These brand names can be traditional (includes the place names, vineyards, wine estate or wine making family name) or non-traditional (using celebrity names, catchy and creative titles). Sherman and Tuten (2011: 231) found that traditional wine brand names are more attractive to consumers. Sáenz-Navajas et al. (2013: 52) concluded that wine origin and the denomination of origin plays an important role in quality perception.

All the elements selected for a specific wine are interrelated and inseparable. According to Barber et al. (2006: 229) the wine market is in need of a relevant and useful marketing message on the packaging. The correct packaging decision is not only important to break through the clutter, but also to safe costs of rebranding or repackaging. Among the bulk of previous studies that dealt with extrinsic cues, most were developed for European countries like France and Italy, the Australian market, America or even China. There is a gap in the literature on instruments to test the South African wine market. The objective of this study is to identify the extrinsic elements of a wine bottle that influence the consumer's quality perception and purchase intention, with specific reference to the front label.

\section{Research Methodology: Phase 1}

To answer the research objective a theoretical model was develop from the literature study to determine which extrinsic cues may affect a South African Pinotage consumer. Seven elements were identified from the theory, namely: Shape of the bottle, Type of closure, Images, Typography (writing of name and font), Colours, Front and back label and the Brand name. Twenty eight statements were used to measure which extrinsic cues (shape of bottle, type of closure. Images, typography, colours, front and back label, brand name and logo) contribute to the consumers' quality and price perception as well as their intention to purchase.

A quantitative self-administrative questionnaire was developed from the above mentioned statements, as well as a few questions on wine consumption. Three bottles of wine were chosen that represented the different components identified from literature. The three elements that were similar about the bottles was the bottles prices range within R40 and all three were a 2011 vintage and the cultivar was Pinotage. This ensured that the instrument can be used by wine marketers to measure their product against their main competitors. 
The Tall Horse was in the bordeaux shaped bottle with a screw cap. This label with its bright coloured giraffe and non-traditional brand name typed in a modern typography can be classified as a novelty label. The front label have minimum information (only brand name, origin, cultivar and year) and a more informative back label including a description of the wine (not the producer), the alcohol percentage, wine volume, a limitation warning for males and females, barcode, the origin and the law required warning.

The Landskroon is a bordeaux shaped bottle with a cork top and with bold, large, roman, uppercase typography. This bottle has a conservative and traditional label with the coat of arms at the bottom, a drawing of the farm entrance and the relevant front label information in dark and neutral colours. The back label had a description of the farm, the wine, serving suggestions, the origin, alcohol percentage, barcode, website address and the law required warning. Landskroon brand name is also a typical traditional name.

The Petit, bottled in a burgundy shaped bottle, with a screw top is an example of a contemporary label, with no images, a mixture of roman and italic sans typography and a light maroon colour, classified as more nontraditional. The brand name in this case differs from the producer, but on the front label both the brand name and producer (Ken Forrester wines) was indicated. The Petit refers to a cheaper product range of the Ken Forrester wines. On the back there is information about the producers, the production process, serving suggestions and product information, as well as the website address of the producer, alcohol percentage, wine volume, and law required warning.

The respondents can be asked to rate the three wines on all the different extrinsic cues. Eighty respondents choose by random sampling, who visited a liquor store during September and occasionally drinks wine, completed the questionnaire. The total sample included $69 \%$ females and $31 \%$ males, $32 \%$ was between the age of $18-24,15 \%$ between $25-30,31 \%$ between $31-50$ and $20 \%$ were older than 50 years. $21 \%$ of the respondents describe themselves as novice, $29 \%$ as less novice, $32 \%$ as neither novice nor expert, $14 \%$ as less expert and $4 \%$ as experts. Most of the respondents drank wine once a week (64\%), while $29 \%$ consume wine $2-3$ times, $7 \%$ of the group drank 4 or more times a week wine.

\section{Results: Phase 1}

The effect of wine packaging elements on consumers' quality and price perception as well as purchase intention was analysed to determine how the extrinsic cues on the wine label influence the Pinotage consumers. The factor values (FV) for every wine (Tallhorse, Landskroon and Petit) and every extrinsic cue were calculated to determine the elements with the highest factor value that influence the quality perception, price perception and purchase intention. Figure 2 shows that Landskroon scored high factor values $(\mathrm{FV}>0.5)$ for all extrinsic cues on the wine label, that indicate that the majority of 
consumers agreed that these seven elements contributed to their quality perception of the Landskroon wine and Pinotage.

Figure 2. Influence of Wine Packaging Elements on Quality Perception

\begin{tabular}{|l|c|c|c|}
\hline & \\
\hline
\end{tabular}

Source: Authors' estimations.

Brand name however scored the highest factor value $(F V=0.788)$ for Landskroon. Brand name can thus be seen as the most significant indicator of quality for respondents of the Landskroon wine, followed by the front label $(\mathrm{FV}=0.747)$ and the typography $(\mathrm{FV}=0.709)$. Tallhorse have the highest factor value for the front label ( $F V=0.506)$, whereas Petit scored a higher factor value for the brand name $(\mathrm{FV}=0.556)$. The other elements of Tallhorse and Petit did not contribute to the quality perception of the respondents.

\section{Purchase Intention}

The wine extrinsic cues on the wine label present on each wine can also influence the purchase intention of consumers. The factor values (FV) for all the elements of all three wines were lower than for the respondents' perception about the wines.

From Figure 3 it is clear that the brand name of Landskroon would motivate consumers the most with a factor value of 0.747 followed by the front label $(\mathrm{FV}=0.675)$ and the back label $(\mathrm{FV}=0.594)$. Only the front label $(\mathrm{FV}=0.538)$ of Tallhorse motivated consumers to buy the wine and the front label $(\mathrm{FV}=0.588)$ of Petit motivated consumers to buy the specific wine. All the other elements did not contribute to the purchase intention of respondents. 
Figure 3. Influence of Wine Packaging Elements on Purchase Intention

\begin{tabular}{|c|c|c|c|c|}
\hline \multirow[t]{2}{*}{ 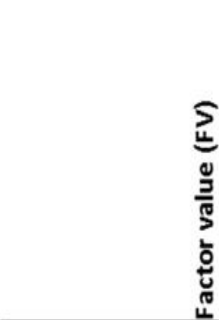 } & \multirow[t]{2}{*}{$\begin{array}{l}0.800 \\
0.700 \\
0.600 \\
0.500 \\
0.400 \\
0.300 \\
0.200 \\
0.100 \\
0.000\end{array}$} & \multirow[b]{2}{*}{ Tallhorse } & \multirow[b]{2}{*}{ Landskroon } & \multirow[b]{2}{*}{ Petit } \\
\hline & & & & \\
\hline \multicolumn{2}{|l|}{ - Shape } & 0.341 & 0.447 & 0.378 \\
\hline \multicolumn{2}{|c|}{ Method of closure (screw) } & 0.419 & 0.000 & 0.422 \\
\hline \multicolumn{2}{|c|}{ Method of closure (cork) } & 0.000 & 0.422 & 0.000 \\
\hline \multicolumn{2}{|l|}{ 口Images } & 0.434 & 0.556 & 0.428 \\
\hline \multicolumn{2}{|l|}{ 口Typography } & 0.384 & 0.578 & 0.453 \\
\hline \multicolumn{2}{|l|}{ Golours } & 0.447 & 0.547 & 0.441 \\
\hline \multicolumn{2}{|l|}{$\square$ Front label } & 0.538 & 0.675 & 0.588 \\
\hline \multicolumn{2}{|l|}{ 口Back label } & 0.463 & 0.594 & 0.488 \\
\hline \multicolumn{2}{|l|}{$\square$ Brand name } & 0.434 & 0.747 & 0.566 \\
\hline
\end{tabular}

Source: Authors' estimations.

\section{Conclusions: Phase 1}

The conclusions from phase 1 of the research are that the various extrinsic cues on wine labels influence Pinotage consumers' quality perceptions as well as their purchase intention. The front label and brand name was found to be influential in terms of all three wines on the consumers' price and quality perception and purchase intention. The front label can be seen as the standard against which quality of wine is measured. Typography and colours used on the label is also important in terms of perceptions of quality. Although the effect of the method of closure had an effect on the quality perception, the effect on the purchase intention was not so significant. Extrinsic cues can thus influence consumers' quality perception, but not necessarily motivate consumers' to buy. The shape of the bottle does not increase the purchase intention and there for wine marketers do not have to rethink their bottling.

\section{Research Methodology: Phase 2}

Eye-tracking methodology provides a detailed documentation of how consumers interact with a computer (thus website) in every single moment (Chu et al. 2009). Eye-tracking allows the gaze of the user to be captured in order to determine exactly where on a stimulus a person looked. Therefore, to identify the preferred extrinsic cues on the label an eye-tracking experiment was conducted in a controlled environment. Participants viewed 12 bottles of wine on a computer screen in the usability laboratory of the University of the Free State's Department of Computer Science and Informatics. Each session 
was strictly conducted according to a fixed eye-tracking protocol that was established before the commencement of the study. Participants were asked to determine the quality of the bottle and to state which part of the label influenced their quality perception the most. $34 \%$ of the participants were male and $66 \%$ were female. $25 \%$ regarded themselves as highly involved when making a wine purchase decision, while $75 \%$ rated them with a low or medium involvement.

\section{Results: Phase 2}

Figure 4 shows the heat maps from the eye-tracking data, as well as the mean of the Quality Perception (QP) on a 5 point-Likert scale (Extremely good quality, good quality, average, poor quality, extremely poor quality) and Purchase Intention also on the 5 point-Likert scale. Bottle B, F, H and L have lower QP and PI, from the interviews during the eye-tracking sessions it is clear that the participants rate a wine as poor quality if cartoon or creative images or pictures are used, as the images is not related to wine, the screw closure also influence their QP and PI, the brand name that is unknown to them and there is not enough information on the bottle. Bottle A, C, D, E, G, I and K have higher QP and PI, the reasons given is the good and well known brand name with a good reputation, the classic and old school look, the use of golden and purple colours, the use of words like "reserved" or "limited edition", the simplicity on the bottles and the classical typography, as well as the vintage that is visible. Purchase intention of Bottle $E$ and $K$ is higher than Quality Perception due to their well-known brands. Bottle B have the lowest of both due to the cartoon characters and no visible known brand. Although Bottle $\mathrm{J}$ is a good quality wine, it is rate low on both QP and PI, due to the brand name that have no wine connection and is unknown to the participants. 
Figure 4. Heatmaps from Eye-Tracking with Quality Perception $(Q P)$ and Purchase Intention (PI)
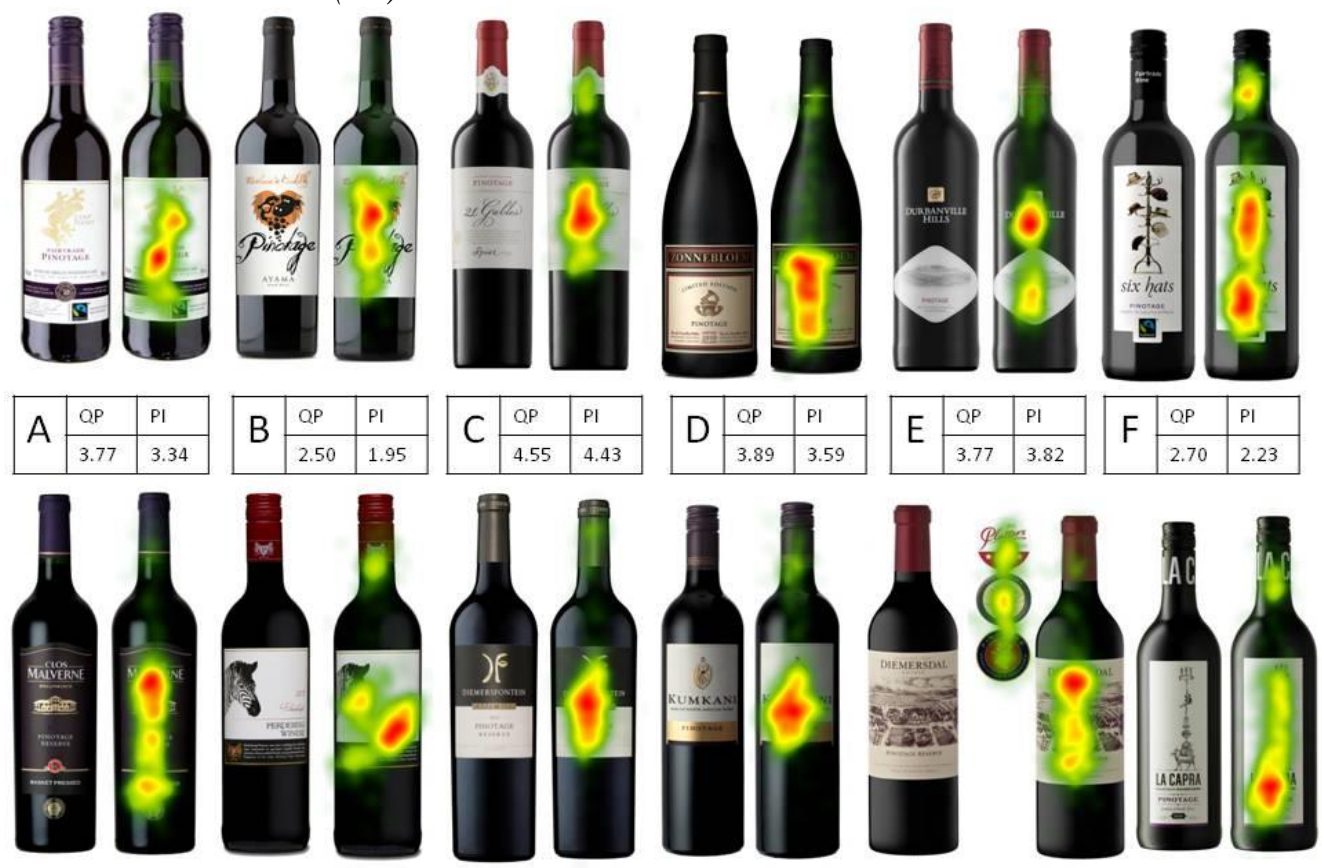

\begin{tabular}{|l|l|l|}
\hline $\mathrm{G}$ & $\mathrm{QP}$ & $\mathrm{PI}$ \\
\cline { 2 - 4 } & 4.34 & 4.02 \\
\hline
\end{tabular}

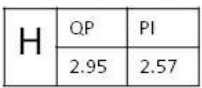

\begin{tabular}{|l|l|l|}
\hline $\mathrm{I}$ & QP & PI \\
\cline { 2 - 3 } & 4.07 & 3.91 \\
\hline
\end{tabular}

\begin{tabular}{|l|l|l|}
\hline \multirow{2}{*}{$J$} & QP & PI \\
\cline { 2 - 4 } & 3.20 & 2.84 \\
\hline
\end{tabular}

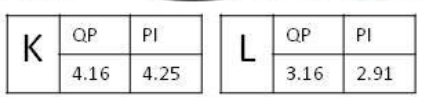

Source: Authors' estimations.

Participant number 42 stated: "If they go through so much effort to design the label, imagine how good the wine is going to be." This summarizes the importance of a front label.

Participants rated the bottles average when the brand was not known, the symbol used was not wine related, the label is too busy or have to little information on or no vintage.

Table 1 shows the average time it took a participant to first notice the specific Area of Interest and the average time a participant view that area within the first 10 seconds after the image have appeared on the screen. 
Table 1. Eye-Tracking Results

\begin{tabular}{|c|c|c|}
\hline Areas of Interest (AoI) & $\begin{array}{l}\text { Average } \\
\text { to first fixation }\end{array}$ & $\begin{array}{l}\text { Average Total } \\
\text { fixation duration }\end{array}$ \\
\hline Grape variety & 1.1 & 1.98 \\
\hline Awards & 1.74 & 2.41 \\
\hline Brand name & 2.33 & 1.01 \\
\hline Image/Picture & 2.39 & 1.35 \\
\hline Vintage & 2.6 & 0.69 \\
\hline Limited/Reserve & 3.05 & 0.8 \\
\hline Information & 3.17 & 0.83 \\
\hline Origin & 3.74 & 0.83 \\
\hline Estate or farm name & 4 & 0.48 \\
\hline Established date & 4.13 & 0.53 \\
\hline Fairtrade & 4.39 & 0.46 \\
\hline Family Shield & 4.59 & 0.76 \\
\hline Top detail & 5.2 & 0.61 \\
\hline Closure & 8.04 & 0.31 \\
\hline
\end{tabular}

Source: Authors' estimations.

\section{Conclusions: Phase 2}

As determined in Phase 1 of the research, brand name has an influence on quality perception a purchase intention. Known brand names with good reputations leads to positive perceptions. Images should be wine related with tradition wine names, not like Kumkani, Baboon Cuddle's, Six Hats or La Capra. Vineyard or the estate in golden and purple colours indicates quality.

When participants determine quality perception and purchase intention they look for the grape variety on the bottle first, secondly the awards, the brand name, image, vintage and if it is a limited edition or reserve wine.

\section{Managerial Implications and Recommendations}

The front label and brand name is of critical importance. Unfortunately it is difficult to change a brand name, once it is known in the market, therefore, when wine marketers choose a brand name; they should ensure that the market is accepted towards the name. The brand name should maintain a sense of authenticity as consumers still prefer traditional above non-traditional brand names. Further research can investigate if the consumer understood the meaning on non-traditional names and the history of it, if it will make a difference.

In reality most wine marketers want to create a wine that can be sold at an reasonable price to make a profit in the end. It is thus necessary for the marketers to consider which elements will indicate an expensive wine and which do not contribute to price perception. Care should be taken to ensure that 
all necessary information is present on the back label as well as ensuring that the back label is easy to read and interperet. The typography should match the total look and feel that the wine marketers and packaging designers want to create. Once again the brand name is an important element wine marketers should consider when their aim is to sell their wines at a premium price.

If the wine being bottled is a special edition or a reserve wine, it should be indicated on the bottle. Wine marketers should ensure that if an award is won by a specific wine that the relevant stickers is on the bottles. The vintage is also important when consumers determine the quality of a wine. The design of the label should rather be simple, but classic and effort should be put into te design and thought process behind a front label.

Wine knowledge and frequency of wine drinking are different in other regions of South Africa than where the study was conducted, there for researchers can refine this instrument more and retest it in different wine drinking regions. Further research can also be conducted by using different wine varieties. Other research studies can focus on the perception of wine based on the extrinsic cues, like in this study, followed by a blind tasting of the wines to compare the perception of packaging and the influence of the taste of the wine. Finally, more research can be conducted on specifically the brand name of wine, as it is proven through the results of this study to be an extremely important element the price perception, quality perception as well as purchase intention. The same label design, but different names can be used to test this.

\section{References}

Atkin T, Johnson R (2010) Appellation as an indicator of quality. International Journal of Wine Marketing 22(1): 42-61.

Barber N, Almanza B (2006) Influence of wine packaging on consumers' decision to purchase. International Foodservice Business Research 9(4): 83-98.

Barber N, Almanza BA, Donovan JR (2006) Motivational factors of gender, income and age on selecting a bottle of wine. International Journal of Marketing 18(3): 218-232.

Bhattacharjee D, Bhattacharjee BJ (2005) Impact of packaging of the buying behaviour of consumers in a communicationally remote urban area. Research Bulletin of the Institute of Cost and Works Accountants of India 27: 200-204.

Boudreaux CA, Palmer SE (2007) A charming little Cabernet: effect of wine label design on purchase intent and brand personality. International Journal of Wine Business Research 19(3): 170-186.

Chaney I (2000) External search effort for wine. International Journal of Wine Marketing 28(1): 5-18.

Charter S, Lockshin L, Unwin T (1999) Consumer responses to wine bottle back labels. Journal of Wine Research 10(3): 95-183.

Charters S (2003) Perceptions of Wine Quality. Doctoral dissertation, Edith Cowan University.

Chrea C, Melo L, Evans G, Forde C, Delahunty C, Cox DN (2011) An investigation using three approaches to understand the influence of extrinsic product cues on 
consumer behavior: an example of Australian wines. Journal of Sensory Studies 26(1): 13-24.

Chu S, Paul N, Ruel L (2009) Using eye tracking technology to examine the effectiveness of design elements on news websites. Information Design Journal 17(1): 31-43.

Corduas M, Cinquanta L, Ievoli C (2013) The importance of wine attributes for purchase decisions: a study of Italian consumers' perception. Food Quality and Preference 28(2): 407-418.

Deng X (2009) Consumer response to visual aspects of packaging and product design. s.l.: University of Pennsylvania.

Douglasgreen (2011) The Shape of a Wine. Retrieved from http://goo.gl/5nJ7Xx. [Accessed: 30 October 2012]

Henley CD, Fowler DC, Yuan J, Stout BL, Goh BK (2011) Label design: impact on millennials' perception of wine. International Journal of Wine Business Research 23(1): 7-20.

Hoyer WD, MacInnis DJ (2010) Consumer Behaviour (5th edn.). s.l.: Cengage Learning.

Immonem L (2010) Package Cues and their Influence on the Perception of Premium Quality of Premium Private Label Products s.1.: s.n.

Louw A, Kimber M (2007) The Power of Packaging. Retrieved from http://goo.gl/28q7e. [Accessed: 10 May 2012]

McGarry Wolf M, Thompson M (2010) The importance of the information on the back label of a wine bottle on the purchase decision. Paper for the pre-AARES conference workshop on The World's Wine Markets by 2030: Terroir, Climate Change, $R \& D$ and Globalization, Adelaide Convention Centre, Adelaide, South Australia, 7-9 February 2010: 2-10.

Mueller S, Lockshin L (2008) How Important is Wine Packaging for Consumers?. Siena: s.n.

Olsen J, Thompsons K, Clarke T (2003) Consumers self-confidence in wine. International Journal of Wine Marketing 15(3): 40-52.

Orth UR, Malkewitz K (2006) Packaging as a Resource for the Construction of Brand Identity. Montpellier: s.n.

Prendergast G, Pitt L (1996) Packaging, marketing, logistic and the environment: are there trade-offs? International Journal of Physical Distribution \& Logistics Management 26(6): 60-72.

Roma P, Di Martino G, Perrone G (2013) What to show on the wine labels: a hedonic analysis of price drivers of Sicilian wines. Applied Economics 45: 2765-2778

Sáenz-Navajas MP, Campo E, Sutan A, Ballester J, Valentin D (2013) Perception of wine quality according to extrinsic cues: the case of Burgundy wine consumers. Food Quality and Preference 27(1): 44-53.

Sherman S, Tuten T (2011) Message on a bottle: the wine label's influence. International Journal of Wine Business Research 23(3): 221-234.

Silayoi P, Speece M (2004) Packaging and purchase decisions: an exploratory study on the impact of involvement level and time pressure. Brititsh Food Journal 106(8): 607-628.

Thomas A (2000) Elements influencing wine purchasing: a New Zealand view. International Journal of Wine Marketing 12(2): 47-62.

Thomas A, Pickering G (2003) The importance of wine label information. International Journal of Wine Marketing 15(2): 58-75. 
Vol. 2, No. 2 Boshoff et al.: South African Perspective of Extrinsic Wine Label Cues

Van Biljon W, Jansen van Rensburg M (2011) Branding and packaging design: key insights on marketing milk to low-income markets in South Africa. African Journal of Business Management 5(22): 9548-9558. 